\title{
Molecular forms of circulating adrenomedullin in patients with congestive heart failure
}

\author{
N Hirayama, K Kitamura, T Imamura, J Kato, Y Koiwaya, \\ T Tsuji ${ }^{1}$, K Kangawa ${ }^{2}$ and T Eto
}

First Department of Internal Medicine, Miyazaki Medical College, 5200 Kihara, Kiyotake, Miyazaki 889-1692, Japan

${ }^{1}$ Shionogi \& Co., Ltd, Mishima, Settsu, Osaka 566-0022, Japan

${ }^{2}$ Department of Biochemistry, National Cardiovascular Center Research Institute, Fujishirodai, Suita, Osaka 565-0873, Japan

(Requests for offprints should be addressed to T Eto)

\begin{abstract}
In the biosynthesis of adrenomedullin (AM), an intermediate form, $\mathrm{AM}(1-52)$-glycine- $\mathrm{COOH}$ (iAM), is cleaved from proAM and subsequently processed to a biologically active mature form, $\mathrm{AM}(1-52)-\mathrm{NH}_{2}$ (mAM), by enzymatic amidation. We recently reported that immunoreactive AM in human plasma consists of mAM and iAM. To clarify the pathophysiological roles of mAM and $\mathrm{AAM}$ in heart failure, we established an assay method to specifically detect $\mathrm{mAM}$, and we determined the plasma concentrations of $\mathrm{MAM}$ and $\mathrm{IAM}$ in 68 patients with congestive heart failure (CHF). The plasma mAM concentrations of the CHF patients classified as being class I or II of New York Heart Association (NYHA) functional classification were significantly greater than those of the 28 healthy controls, and a further increase was noted in the class III or IV patients. Similar increases in plasma iAM
\end{abstract}

were also observed in these patients compared with controls. The increased plasma mAM and iAM in 12 patients with exacerbated CHF were significantly reduced by treatment of their CHF for 7 days. In addition, the plasma concentrations of both mAM and iAM were significantly correlated with pulmonary capillary wedge pressure, pulmonary artery pressure, right atrial pressure, cardiothoracic ratio, heart rate, and the plasma concentrations of atrial and brain natriuretic peptides in the CHF patients. Thus the plasma concentrations of both mAM and iAM were increased progressively in proportion to the severity of CHF. These results suggest that, though the role of iAM remains to be clarified, mAM acts against the further deterioration of heart failure in patients with CHF. Journal of Endocrinology (1999) 160, 297-303

\section{Introduction}

Human adrenomedullin (AM) is a potent vasodilator peptide consisting of 52 amino acid residues with an amidated C-terminal tyrosine and a ring structure formed by an intramolecular disulfide bond (Kitamura et al. 1993). Besides its vasodilator effect, AM has been shown to increase the glomerular filtration rate (Hirata et al. 1995) and to inhibit aldosterone secretion (Yamaguchi et al. 1996). The development of a radioimmunoassay (RIA) for AM revealed that immunoreactive $A M$ is present in human blood in the low picomolar range (Ichiki et al. 1994, Kitamura et al. 1994a, Lewis et al. 1998). These findings imply a possible role of AM in modulating cardiovascular homeostasis. The structures of porcine (Kitamura et al. 1994b), rat (Sakata et al. 1993) and mouse (Okazaki et al. 1996) AM showed a well-conserved amino acid sequence among species, particularly in the ring structure and the C-terminal amidated tyrosine residue, suggesting the importance of these two portions of the AM molecule for its biological activity. In fact, both the ring and C-terminal amide structures were reported to be essential for the receptor binding and the production of intracellular cAMP, a major second messenger of AM, in cultured vascular smooth muscle cells (Eguchi et al. 1994). In the processing of AM, an intermediate form, $\mathrm{AM}(1-52)$-glycine-COOH (iAM), is believed to be cleaved from proAM and subsequently processed to a biologically active mature form, $\mathrm{AM}(1-52)-\mathrm{NH}_{2}$ (mAM), by an amidation enzyme. We recently reported that immunoreactive AM in the human plasma consists, not only of mAM, but also of iAM, which is converted to $\mathrm{mAM}$ in the presence of the amidation enzyme in vitro (Kitamura et al. 1998). A number of reports have shown that the plasma concentrations of AM are increased in patients with congestive heart failure (CHF) (Jougasaki et al. 1995, Nishikimi et al. 1995, Kato et al. 1996, Kobayashi et al. 1996); however, the molecular forms of plasma AM have not been examined. In those previous studies, the plasma AM concentration was determined by 
Table 1 Clinical characteristics of controls and heart failure patients. Values are means \pm S.E.M.

\begin{tabular}{|c|c|c|c|}
\hline & \multirow[b]{2}{*}{ Controls } & \multicolumn{2}{|c|}{ Patients with CHF (NYHA functional class) } \\
\hline & & Class I or II & Class III or IV \\
\hline$n$ & 28 & 48 & 20 \\
\hline Age (years) & $61 \cdot 9 \pm 1 \cdot 8$ & $62 \cdot 1 \pm 1 \cdot 7$ & $65 \cdot 5 \pm 3 \cdot 0$ \\
\hline $\operatorname{Sex}(M / F)$ & $18 / 10$ & $34 / 14$ & $8 / 12$ \\
\hline \multicolumn{4}{|l|}{ Primary cause of $\mathrm{CHF}$} \\
\hline IHD & - & 27 & 9 \\
\hline Valvular & - & 9 & 7 \\
\hline DCM & - & 3 & 2 \\
\hline HHD & - & 3 & 1 \\
\hline Congenital & - & 3 & 0 \\
\hline Other & - & 3 & 0 \\
\hline Serum creatinine (mg/dl) & $0 \cdot 7 \pm 0 \cdot 1$ & $0 \cdot 9 \pm 0 \cdot 1$ & $0 \cdot 9 \pm 0 \cdot 1$ \\
\hline Body mass index $\left(\mathrm{kg} / \mathrm{m}^{2}\right)$ & $23 \pm 0 \cdot 5$ & $22 \cdot 9 \pm 0 \cdot 6$ & $23 \cdot 0 \pm 1 \cdot 4$ \\
\hline Systolic BP $(\mathrm{mmHg})$ & $125 \pm 5$ & $133 \pm 5$ & $130 \pm 10$ \\
\hline Diastolic BP (mmHg) & $75 \pm 2$ & $72 \pm 3$ & $74 \pm 6$ \\
\hline Heart rate (beats/min) & $66 \cdot 5 \pm 2 \cdot 8$ & $69 \cdot 1 \pm 2 \cdot 0^{*}$ & $102 \cdot 0 \pm 6 \cdot 0^{*} \dagger$ \\
\hline CTR $(\%)$ & $47 \cdot 1 \pm 1 \cdot 5$ & $51 \cdot 9 \pm 1 \cdot 4^{*}$ & $65 \cdot 6 \pm 0.9^{*} \dagger$ \\
\hline $\operatorname{LVEF}(\%) \ddagger$ & $71 \cdot 5 \pm 1 \cdot 0$ & $65 \cdot 3 \pm 2 \cdot 5^{*}$ & $41 \cdot 5 \pm 5 \cdot 3^{*} \dagger$ \\
\hline Plasma ANP (fmol/ml) & $3 \cdot 3 \pm 0 \cdot 4$ & $12 \cdot 0 \pm 2 \cdot 8^{*}$ & $50 \cdot 0 \pm 9 \cdot 8^{*} \dagger$ \\
\hline Plasma BNP (fmol/ml) & $2 \cdot 5 \pm 0 \cdot 4$ & $24 \cdot 7 \pm 5 \cdot 7^{*}$ & $255 \cdot 2 \pm 54 \cdot 5^{*} \dagger$ \\
\hline
\end{tabular}

P<0.001: *compared with controls; tcompared with class I or class II. IHD, ischemic heart disease; DCM, dilated cardiomyopathy; HHD, hypertensive heart disease; BP, blood pressure; CTR,

cardiothoracic ratio. ‡Determined by echocardiography.

RIAs unable to distinguish mAM from iAM, and was thereby measured as total AM (tAM) concentration.

In the present study, we established a specific, sensitive assay method to measure the human plasma mAM concentration. Using this assay, we examined the plasma concentrations of mAM and iAM in patients with CHF and compared them with those in control subjects, in order to clarify the pathophysiological roles of mAM and $\mathrm{iAM}$.

\section{Materials and Methods}

\section{Study patients and blood sampling}

Sixty-eight patients with chronic CHF caused by various heart disorders were enrolled in the study (42 men and 26 women; 26-85 years of age) and classified into two groups according to their New York Heart Association (NYHA) functional class (Table 1). Patients who had impaired renal function with a serum creatinine concentration $>177 \mu \mathrm{mol} / 1(2 \cdot 0 \mathrm{mg} / \mathrm{dl})$, severe liver dysfunction, or lung or inflammatory disease were excluded. The diagnosis of the primary cause of $\mathrm{CHF}$ was made on the basis of clinical histories, physical examinations, chest X-rays, electrocardiograms, and echocardiograms, in addition to the cardiac catheterization data. All the patients with symptomatic heart failure were receiving medications such as diuretics, digitalis, $\beta$-blockers, angiotensin-converting enzyme inhibitors, $\mathrm{Ca}$ channel blockers or nitrates as needed. The mAM and IAM concentrations in 12 of the 20 patients in class III or IV, who were admitted to our hospital because of an exacerbation of CHF, were evaluated repeatedly before and during the treatment for CHF. Their clinical symptoms were relieved after the treatment, and echocardiography and chest X-ray were performed at day 7 after admission in these patients. Twenty-eight healthy subjects aged 37-79 years served as controls. Informed consent for all the procedures was obtained from each study participant.

Blood was drawn from the antecubital vein or the femoral vein after the subject had undergone an overnight fast and $30 \mathrm{~min}$ of supine rest, on the day when the heart catheterization study or echocardiography was performed. Blood samples were collected in chilled tubes with $1 \mathrm{mg} / \mathrm{ml}$ disodium ethylenediaminetetra-acetic acid (EDTA-2Na) and $500 \mathrm{KIU} / \mathrm{ml}$ aprotinin, and centrifuged at $4{ }^{\circ} \mathrm{C}$. Plasma samples were kept at $-40{ }^{\circ} \mathrm{C}$ until required for use.

\section{Cardiac catheterization}

Right-sided heart catheterization was performed in 47 of the CHF patients, with a 7F Swan-Ganz catheter (model $131 \mathrm{H}$, Baxter Healthcare Corporation, Irvine, CA, USA), and left ventricular contrast studies were performed in 39 patients with 6F pigtail catheters (model 7779-B3, Mallinckrodt Medical Inc., St Louis, MO, USA). Cardiac output was measured by the thermodilution method in 43 
patients and by Fick's method in four patients. The left ventricular ejection fraction (LVEF) and left ventricular end-diastolic/systolic volume were calculated by the area-length method.

\section{Preparation of antisera for $A M$}

Three types of antisera were raised against human AM and its fragment peptides. Entire-AM-antibody (E-AM-Ab) shows $100 \%$ cross-reactivity with mAM (AM(1-52)$\mathrm{NH}_{2}$ ) and iAM (AM(1-52)-glycine-COOH) (Kitamura et al. 1998). C-terminal-AM-antibody (C-AM-Ab) specifically recognizes the C-terminal amide structure of the AM molecule and has no cross-reactivity with iAM, calcitonin gene-related peptide (CGRP) or neuropeptide Y (Ichiki et al. 1994). E-AM-Ab and C-AM-Ab were prepared as reported elsewhere (Ichiki et al. 1994, Kitamura et al. 1994a). A monoclonal antibody for the ring structure (R-AM-Ab) was raised by a standard method. Briefly, human AM(12-25) was conjugated to bovine thyroglobulin (Sigma) by the carbodiimide coupling procedure. The conjugate containing $18.1 \mu \mathrm{g}$ peptide dissolved in saline was emulsified with Freund's complete adjuvant and then injected subcutaneously into 5-weekold female $\mathrm{BALB} / \mathrm{c}$ mice eight times at 3-week intervals. Spleen cells of the immunized mice were fused with cells of the mouse myeloma line, X63-Ag8.653 (Galfré \& Milstein 1981). The hybridoma culture media were screened periodically for the ability to bind $\left[{ }^{125}\right.$ I] human AM. Cells from the well with the highest titer were cloned by limiting dilution and then injected intraperitoneally to $\mathrm{BALB} / \mathrm{c}$ mice. R-AM-Ab specifically recognizes the ring structure of the AM molecule and has no cross-reactivity with CGRP, amylin or rat AM.

\section{Assays for $m A M$ and $t A M$}

Ten milliliters plasma were acidified by adding $120 \mu \mathrm{l}$ $1.0 \mathrm{~mol} / 1 \mathrm{HCl}$ and diluted with $10 \mathrm{ml}$ saline. The plasma was then loaded to a Sep-Pak C18 cartridge that had been activated by washing with $5 \mathrm{ml} 60 \%$ acetonitrile containing $0 \cdot 1 \%$ trifluoroacetic acid followed by $5 \mathrm{ml}$ saline. After washing with $5 \mathrm{ml}$ saline, absorbed material was eluted with $4 \mathrm{ml} 60 \%$ acetonitrile containing $0 \cdot 1 \%$ trifluoroacetic acid. The eluate was lyophilized and dissolved in $450 \mu \mathrm{l}$ RIA buffer, $50 \mathrm{mmol} / 1$ sodium phosphate buffer $(\mathrm{pH} 7 \cdot 4)$ containing $0.5 \%$ BSA treated with $0.5 \%$ N-ethylmaleimide, $0 \cdot 5 \%$ Triton X-100, $80 \mathrm{mmol} / 1 \mathrm{NaCl}$, $25 \mathrm{mmol} / 1$ EDTA-2Na, 0.05\% $\mathrm{NaN}_{3}$, and $500 \mathrm{KIU} / \mathrm{ml}$ aprotinin. AM peptides having the ring structure were purified by immunoprecipitation. Fifty microliters $1 \%$ $\gamma$-globulin containing R-AM-Ab diluted at 1:1000 were added to the plasma extract. After an incubation for $4 \mathrm{~h}$ at $4{ }^{\circ} \mathrm{C}, 500 \mu \mathrm{l} 23 \%$ polyethyleneglycol was added and the mixture stirred vigorously, allowed to stand for $20 \mathrm{~min}$, and centrifuged for $30 \mathrm{~min}$ at 3000 r.p.m. After the supernatant was aspirated, the precipitate was dissolved in $500 \mu \mathrm{l} 1 \mathrm{~mol} / \mathrm{l}$ acetic acid and boiled for $10 \mathrm{~min}$ to inactivate $\mathrm{R}-\mathrm{AM}-\mathrm{Ab}$. The samples were then lyophilized and stored at $-40{ }^{\circ} \mathrm{C}$ until the RIAs. About $75 \%$ of the $\left[{ }^{125} \mathrm{I}\right] \mathrm{AM}$ or synthetic AM added to the plasma sample was reproducibly recovered by this immunoprecipitation procedure. The extract was dissolved in $300 \mu \mathrm{l}$ RIA buffer and subjected to either an RIA for tAM (E-AM-RIA) with E-AM-Ab or an RIA for mAM (C-AM-RIA) with $\mathrm{C}-\mathrm{AM}-\mathrm{Ab}$. These RIA procedures have been described previously (Ichiki et al. 1994, Kitamura et al. 1994a). The intra- and interassay coefficients of variance in the RIA for tAM were $5 \%$ and $8 \%$, and those in the RIA for mAM were $6 \%$ and $9 \%$, respectively.

\section{Characterization of $t A M$ and $m A M$ in human plasma}

The plasma extract was analyzed by reverse-phase highperformance liquid chromatography (HPLC). The extract of $37 \mathrm{ml}$ human plasma was immunoprecipitated by the $\mathrm{R}-\mathrm{AM}-\mathrm{Ab}$. After the precipitate had been boiled in $1 \mathrm{~mol} / 1$ acetic acid for $10 \mathrm{~min}$, the solution was subjected to an HPLC column of TSK-ODS 120A $(4.6 \times 150 \mathrm{~mm}$, Tosoh, Japan). A 60-min linear gradient of $\mathrm{CH}_{3} \mathrm{CN}$ from 10 to $60 \%$ was made in $0 \cdot 1 \%$ trifluoroacetic acid at a flow rate of $1 \mathrm{ml} / \mathrm{min}$. One milliliter eluate was collected every $1 \mathrm{~min}$, and each fraction was subjected to the C-AM-RIA or E-AM-RIA.

\section{Assay procedures for ANP and BNP}

As markers of severity of the heart failure, the plasma concentrations of atrial and brain natriuretic peptides (ANP and BNP) were measured by RIAs (Shiono RIA ANP kit and Shiono RIA BNP kit, Shionogi Co., Osaka, Japan). The accuracies and procedural details of these assays have been described previously (Yasue et al. 1994).

\section{Statistical analysis}

All values are means \pm s.E.M. Multiple groups were compared by either one-way analysis of variance followed by Scheffe's test or $\chi^{2}$ test. Correlations between two variables were evaluated by simple regression analysis. The time course data before and during the treatment were examined by the Wilcoxon signed-rank test. A $P$ value of less than 0.05 was considered statistically significant.

\section{Results}

\section{Characterization of immunoprecipitated materials}

To characterize the immunoreactive AM obtained by the $\mathrm{R}-\mathrm{AM}-\mathrm{Ab}$ immunoprecipitation procedure, the extract was analyzed by reverse-phase HPLC coupled with either 


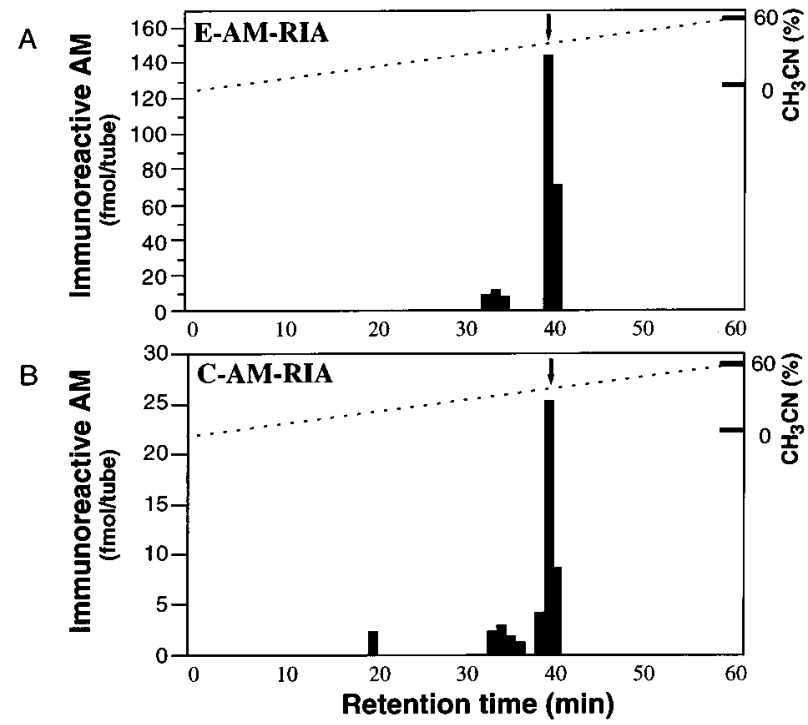

Figure 1 Reverse phase HPLC of immunoreactive AM in human plasma extract immunoprecipitated by the anti-AM antibody against the ring structure (R-AM-Ab). The arrows show the elution position of synthetic human $\mathrm{AM}(1-52)-\mathrm{NH}_{2}$ and human AM(1-52)-glycine- $\mathrm{COOH}$.

the C-AM-RIA specifically recognizing the C-terminal amide structure or the E-AM-RIA, which detects the entire AM structure whether or not the C-terminus is amidated. One major immunoreactive peak emerged in the E-AM-RIA at a position where authentic AM(1-52)$\mathrm{NH}_{2}$ and $\mathrm{AM}(1-52)$-glycine- $\mathrm{COOH}$ were eluted (Fig. 1A). Similarly, more than $90 \%$ of the immunoreactive AM detected by the C-AM-RIA was eluted at exactly the same position as that of the E-AM-RIA (Fig. 1B). However, the immunoreactive AM measured by the C-AM-RIA was much less than that measured by the E-AM-RIA. On the basis of the findings of these HPLC analyses and the cross-reactivities of E-AM-Ab and $\mathrm{C}-\mathrm{AM}-\mathrm{Ab}$, in addition to the results of our previous HPLC analyses (Kitamura et al. 1998), in the present study we calculated the iAM values by subtracting the mAM values from the tAM values.

\section{Clinical characteristics of study subjects}

Table 1 gives the clinical profiles of the study subjects. There were no significant differences in age, sex, serum concentration of creatinine, body mass index, or systolic and diastolic blood pressures among the three subject groups. There were no significant differences between the two CHF groups in the primary causes of CHF. The heart rate, cardiothoracic ratio and plasma ANP and BNP concentrations in the CHF groups were significantly $(P<0 \cdot 001)$ increased compared with those in the control group, and values of these parameters in the functional classes III or IV were significantly $(P<0 \cdot 001)$ greater than those in classes I or II. As expected, the LVEF was progressively $(P<0 \cdot 001)$ reduced in relation to the severity of CHF.

\section{Plasma $m A M$, $i A M$ and $t A M$ concentrations}

Table 2 shows the plasma concentrations of mAM, iAM and tAM and the ratio of $\mathrm{MAM}$ to tAM in the CHF patients, subgrouped according to their NYHA functional classification, and in the control subjects. The plasma $\mathrm{mAM}$ in the class I or II patients was significantly greater than that in the control group $(P<0 \cdot 01)$, and a further increase was noted in the class III or IV patients compared with the controls $(P<0 \cdot 001)$ and the class I or II patients $(P<0 \cdot 001)$. Similar increases in the plasma iAM and tAM were also observed in the class III or IV patients compared with the controls $(P<0 \cdot 001)$ and class I or II patients $(P<0 \cdot 001)$. However, the $\mathrm{mAM} / \mathrm{tAM}$ ratio, ranging from $0 \cdot 24$ to $0 \cdot 29$, showed no significant differences among the three groups. Table 3 shows the correlations between the plasma mAM or iAM concentrations and clinical parameters. Plasma mAM and iAM were significantly correlated with the mean pulmonary capillary wedge pressure, systolic pulmonary artery pressure and mean right atrial pressure. The cardiothoracic ratio, heart rate and ANP and BNP concentrations were also significantly correlated with both the plasma mAM and iAM. The systolic blood pressure of the aorta, cardiac index, left ventricular enddiastolic/systolic volumes, LVEF and left ventricular dimension were not correlated with the plasma mAM and iAM concentrations.

\section{Plasma $m A M$ and $i A M$ concentrations before and} after treatment

As shown in Table 4, in 12 class III or IV patients with exacerbated $\mathrm{CHF}$, the cardiothoracic ratio, left atrial dimension, left ventricular dimension and plasma ANP and BNP concentrations were significantly decreased and the LVEF was significantly increased after CHF treatment for 7 days. The increased plasma mAM and iAM concentrations were significantly reduced, from $1.54 \pm 0 \cdot 12$ to $1.03 \pm 0.08 \quad(P<0.01)$ and from $6.24 \pm 0.89$ to $3.64 \pm 0.27 \mathrm{fmol} / \mathrm{ml} \quad(P<0 \cdot 05)$, respectively, after the treatment (Fig. 2).

\section{Discussion}

Human AM consists of 52 amino acid residues with a C-terminal amidated $\mathrm{Tyr}^{52}$ and a ring structure formed by an intramolecular disulfide bond of $\mathrm{Cys}^{16}$ and $\mathrm{Cys}^{21}$ (Kitamura et al. 1993). Immunoreactive AM has been shown to be present in human plasma and tissues such as adrenal medulla, lung, kidney, cardiac atrium and 
Table 2 Plasma concentrations of AMs and ratio of mAM/tAM in controls and patients with heart failure. Values are means \pm S.E.M.

\begin{tabular}{|c|c|c|c|}
\hline & \multirow[b]{2}{*}{ Controls } & \multicolumn{2}{|c|}{ Patients with CHF (NYHA functional class } \\
\hline & & Class I or II & Class III or IV \\
\hline $\mathrm{mAM}(\mathrm{fmol} / \mathrm{ml})$ & $0 \cdot 65 \pm 0.06$ & $1 \cdot 01 \pm 0.07^{*}$ & $1 \cdot 66 \pm 0 \cdot 12^{* *} 9+\dagger$ \\
\hline $\mathrm{iAM}(\mathrm{fmol} / \mathrm{ml})$ & $2 \cdot 15 \pm 0 \cdot 12$ & $2 \cdot 51 \pm 0 \cdot 19$ & $5 \cdot 39 \pm 0 \cdot 66^{* *}+\dagger$ \\
\hline $\mathrm{tAM}(\mathrm{fmol} / \mathrm{ml})$ & $2 \cdot 80 \pm 0 \cdot 14$ & $3 \cdot 52 \pm 0 \cdot 24$ & $7 \cdot 04 \pm 0 \cdot 71^{* *}+\dagger$ \\
\hline $\mathrm{mAM} / \mathrm{tAM}(\%)$ & $23 \cdot 9 \pm 1 \cdot 6$ & $29 \cdot 3 \pm 1 \cdot 5$ & $26 \cdot 6 \pm 2 \cdot 4$ \\
\hline
\end{tabular}

${ }^{*} P<0 \cdot 01,{ }^{* *} P<0 \cdot 001$, compared with controls; $\dagger+P<0 \cdot 001$, compared with class I or class II.

Table 3 Coefficients for correlation between the plasma mAM or iAM and clinical parameters. Statistically significant values of $P$ are in italics

\begin{tabular}{|c|c|c|c|c|}
\hline & \multicolumn{2}{|l|}{ mAM } & \multicolumn{2}{|l|}{ iAM } \\
\hline & $r$ & $P$ & $r$ & $P$ \\
\hline \multicolumn{5}{|l|}{ Parameter } \\
\hline \multicolumn{5}{|l|}{ Pressure } \\
\hline Pulmonary capillary wedge (mean) & $0 \cdot 63$ & $<0.01$ & $0 \cdot 64$ & $<0 \cdot 01$ \\
\hline Pulmonary artery (systolic) & $0 \cdot 54$ & $<0.01$ & $0 \cdot 45$ & $<0 \cdot 01$ \\
\hline Right atrium (mean) & $0 \cdot 64$ & $<0.01$ & $0 \cdot 58$ & $<0 \cdot 01$ \\
\hline Left ventricle (end-diastolic) & $-0 \cdot 07$ & $0 \cdot 66$ & $0 \cdot 33$ & $<0 \cdot 05$ \\
\hline Aorta (systolic) & $-0 \cdot 11$ & $0 \cdot 27$ & -0.03 & $0 \cdot 74$ \\
\hline Cardiac index & $0 \cdot 12$ & $0 \cdot 45$ & $0 \cdot 15$ & $0 \cdot 36$ \\
\hline End-diastolic volume (left ventricle) & $-0 \cdot 12$ & $0 \cdot 48$ & -0.03 & $0 \cdot 85$ \\
\hline End-systolic volume (left ventricle) & $-0 \cdot 07$ & $0 \cdot 69$ & $-0 \cdot 12$ & $0 \cdot 46$ \\
\hline LVEF & $-0 \cdot 07$ & $0 \cdot 65$ & $-0 \cdot 21$ & $0 \cdot 20$ \\
\hline Left atrial dimension & $0 \cdot 25$ & $<0.05$ & $0 \cdot 18$ & $0 \cdot 12$ \\
\hline Left ventricular dimension (diastolic) & $0 \cdot 03$ & $0 \cdot 80$ & $0 \cdot 16$ & $0 \cdot 17$ \\
\hline CTR & $0 \cdot 51$ & $<0.01$ & $0 \cdot 55$ & $<0 \cdot 01$ \\
\hline Heart rate & $0 \cdot 59$ & $<0.01$ & $0 \cdot 56$ & $<0 \cdot 01$ \\
\hline Plasma ANP & $0 \cdot 49$ & $<0.01$ & $0 \cdot 49$ & $<0 \cdot 01$ \\
\hline Plasma BNP & $0 \cdot 40$ & $<0.01$ & $0 \cdot 50$ & $<0 \cdot 01$ \\
\hline
\end{tabular}

Table 4 Effect of treatment for CHF in 12 patients of NYHA class III or IV. Values are means \pm S.E.M.

\begin{tabular}{|c|c|c|}
\hline & Before treatment & After treatment \\
\hline \multicolumn{3}{|l|}{ Parameter } \\
\hline CTR (\%) & $65 \cdot 2 \pm 1 \cdot 6$ & $60 \cdot 2 \pm 1 \cdot 6^{*}$ \\
\hline Left atrial dimension $(\mathrm{mm})$ & $44 \cdot 4 \pm 1 \cdot 3$ & $37 \cdot 6 \pm 1 \cdot 8^{*}$ \\
\hline Left ventricular dimension (diastolic) (mm) & $60 \cdot 3 \pm 2 \cdot 5$ & $54 \cdot 1 \pm 2 \cdot 1^{*}$ \\
\hline $\operatorname{LVEF}(\%)$ & $29 \cdot 8 \pm 4 \cdot 6$ & $40 \cdot 6 \pm 5 \cdot 1^{*}$ \\
\hline Plasma ANP (fmol/ml) & $40 \cdot 9 \pm 7 \cdot 3$ & $30 \cdot 0 \pm 7 \cdot 1^{* *}$ \\
\hline Plasma BNP (fmol/ml) & $247 \cdot 4 \pm 53 \cdot 5$ & $116 \cdot 5 \pm 48 \cdot 8^{*}$ \\
\hline
\end{tabular}

ventricle (Ichiki et al. 1994, Kitamura et al. 1994a), and the plasma AM was reported to be increased in patients with hypertension or heart failure (Ishimitsu et al. 1994, Kitamura et al. 1994a, Jougasaki et al. 1995, Nishikimi et al. 1995, Kato et al. 1996, Kobayashi et al. 1996). We recently found, by chromatographic analyses, that the immunoreactive AM in human plasma consists of two molecular forms of AM: mAM, AM(1-52)- $\mathrm{NH}_{2}$, and
iAM, a glycine-extended intermediate form of AM that is converted to $\mathrm{mAM}$ by an amidation enzyme (Kitamura et al. 1998). There have been a number of reports on the measurement of plasma AM; however, the plasma AM concentrations were determined by RIAs unable to distinguish mAM from IAM in these studies. It has been shown that both the ring and C-terminal amide structures of AM are essential for the receptor binding and the 

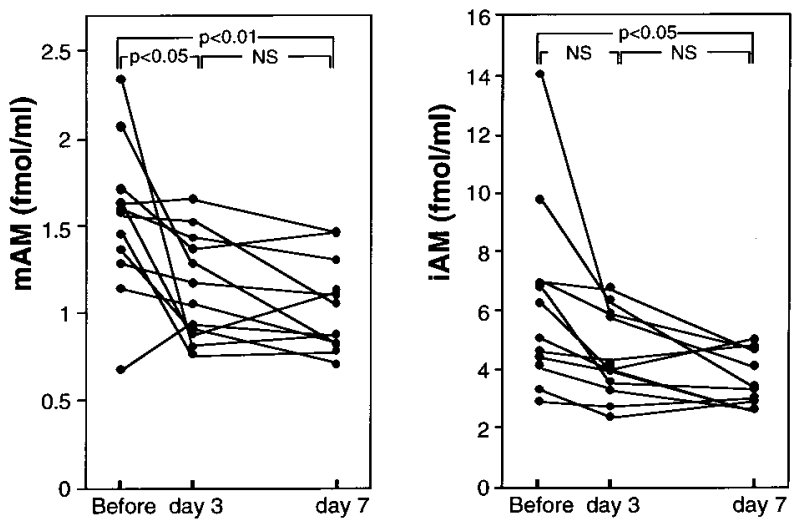

Figure 2 Plasma $\mathrm{mAM}$ and $\mathrm{iAM}$ concentrations before and after treatment in 12 patients with congestive heart failure. NS, not significant.

production of intracellular cAMP in cultured vascular smooth muscle cells (Eguchi et al. 1994). In accordance with this, we found that synthetic iAM exerts a much weaker hypotensive effect compared with that of mAM when injected intravenously to rats (unpublished observation). In the present study, we established a specific assay method to measure the mAM in human plasma. As described in Materials and Methods, AM peptide having the ringed structure in plasma was purified by immunoprecipitation with a monoclonal antibody against human AM(12-25), and subsequently subjected to either an RIA that specifically detects the C-terminal amide structure of $\mathrm{AM}$, for the measurement of $\mathrm{mAM}$, or an RIA recognizing $\mathrm{mAM}$ and iAM equally, for the measurement of tAM. As shown in Table 2, the mean plasma concentrations of $\mathrm{mAM}$ and $\mathrm{tAM}$ in the control subjects were found to be 0.65 and $2.80 \mathrm{fmol} / \mathrm{ml}$, respectively, and thus the calculated iAM value was $2 \cdot 15 \mathrm{fmol} / \mathrm{ml}$.

In the present study, we determined the plasma concentrations of the two molecular forms of AM separately in patients with CHF, and found that both the mAM and iAM concentrations were similarly increased in these patients compared with the controls. The increased mAM concentrations were significantly correlated with the pulmonary capillary wedge pressure, pulmonary artery pressure, right atrial pressure, and the plasma concentrations of ANP and BNP. Nishikimi et al. (1995) reported a significant correlation between plasma tAM and LVEF, an indicator for left ventricular dysfunction, in patients with heart failure, whereas a significant relationship was not found in this study, despite the constant ratio of mAM/ tAM. This discrepancy may be partially explained by the primary causes of heart failure or by severity of the left ventricular dysfunction in the patients studied. In any case, the present results appear to support our hypothesis that the increased plasma AM is related to the retention of fluid volume in patients with $\mathrm{CHF}$, probably acting as a defensive mechanism in heart failure, through its vasodilator and natriuretic effects. It should be noted that the plasma concentrations of mAM were lower than those of iAM, and the major molecular form of immunoreactive AM in human plasma is iAM. However, a chronically infused low dose of $\mathrm{AM}(1-52)-\mathrm{NH}_{2}$ has been shown to decrease blood pressure, reducing plasma renin activity and the aldosterone concentration, at a plasma concentration of $1 \mathrm{fmol} / \mathrm{ml}$ (Khan et al. 1997) - a value observed for the plasma mAM in the present study. Taken together with the reduction in the plasma $\mathrm{mAM}$ after the treatment for $\mathrm{CHF}$, this suggests that mAM may have a role acting against a further deterioration of heart failure in the $\mathrm{CHF}$ patients.

Another finding noted in the present study was that the plasma iAM concentration was similarly increased in patients with CHF, and reduced by the treatment for heart failure, as was plasma mAM. In addition, similar correlations were found between the plasma iAM and clinical parameters. As mentioned above, it is true that synthetic iAM is much less bioactive than mAM. We previously found a conversion of $\mathrm{AAM}$ in human plasma to mAM in the presence of recombinant amidation enzymes in vitro (Kitamura et al. 1998). Recently, it was reported that the glycine-extended substance P (SP) is converted to SP$\mathrm{NH}_{2}$, a biologically active form, in the wall of rat aorta (Oldham et al. 1997). It may therefore be possible that iAM in the plasma is enzymatically processed to mAM, presumably acting as a hormone reservoir for $\mathrm{mAM}$, in patients with CHF. In any case, further studies are necessary to determine the pathophysiological role of plasma iAM in patients with heart failure.

In summary, we developed a sensitive assay method to specifically detect $\mathrm{mAM}$ in human plasma, and we determined the plasma concentrations of $\mathrm{MAM}$ and $\mathrm{iAM}$ in patients with CHF. The plasma concentrations of mAM and iAM were similarly increased in relation to the severity of heart failure in these patients compared with controls. Although the role of the plasma iAM remains to be elucidated, mAM may act as defense mechanism against a further deterioration of heart failure in patients with CHF.

\section{Acknowledgement}

We thank Miss Mari Kawamoto for her excellent technical assistance.

\section{References}

Eguchi S, Hirata Y, Iwasaki H, Sato K, Watanabe T, Inui T, Nakajima S, Sakakibara S \& Marumo F 1994 Structure-activity relationship of adrenomedullin, a novel vasodilatory peptide, in cultured rat vascular smooth muscle cells. Endocrinology 135 $2454-2458$ 
Galfré C \& Milstein C 1981 Preparation of monoclonal antibodies: strategies and procedures. Methods in Enzymology 73(B) 3-46.

Hirata Y, Hayakawa H, Suzuki E, Ikenouchi H, Kohmoto O, Kimura K, Kitamura K, Eto T, Kangawa K, Matsuo H \& Omata M 1995 Mechanism of adrenomedullin-induced vasodilation in the rat kidney. Hypertension 25 790-795.

Ichiki Y, Kitamura K, Kangawa K, Kawamoto M, Matsuo H \& Eto T 1994 Distribution and characterization of immunoreactive adrenomedullin in human tissue and plasma. FEBS Letters 338 6-10.

Ishimitsu T, Nishikimi T, Saito Y, Kitamura K, Eto T, Kangawa K, Matsuo H, Omae T \& Matsuoka H 1994 Plasma levels of adrenomedullin, a newly identified hypotensive peptide, in patients with hypertension and renal failure. Journal of Clinical Investigation 94 2158-2161.

Jougasaki M, Wei C-M, McKinley LJ \& Burnett JC 1995 Elevation of circulating and ventricular adrenomedullin in human congestive heart failure. Circulation 92 286-289.

Kato J, Kobayashi K, Etoh T, Tanaka M, Kitamura K, Imamura T, Koiwaya Y, Kangawa K \& Eto T 1996 Plasma adrenomedullin concentration in patients with heart failure. Journal of Clinical Endocrinology and Metabolism 81 180-183.

Khan AI, Kato J, Kitamura K, Kangawa K \& Eto T 1997 Hypotensive effect of chronically infused adrenomedullin in conscious Wistar-Kyoto and spontaneously hypertensive rats. Clinical and Experimental Pharmacology and Physiology 24 139-142.

Kitamura K, Kangawa K, Kawamoto M, Ichiki Y, Nakamura S, Matsuo H \& Eto T 1993 Adrenomedullin: a novel hypotensive peptide isolated from human pheochromocytoma. Biochemical and Biophysical Research Communications 192 553-560.

Kitamura K, Ichiki Y, Tanaka M, Kawamoto M, Emura J, Sakakibara S, Kangawa K, Matsuo H \& Eto T 1994a Immunoreactive adrenomedullin in human plasma. FEBS Letters 341 288-290.

Kitamura K, Kangawa K, Kojima M, Ichiki Y, Matsuo H \& Eto T $1994 b$ Complete amino acid sequence of porcine adrenomedullin and cloning of cDNA encoding its precursor. FEBS Letters $\mathbf{3 3 8}$ 306-310.

Kitamura K, Kato J, Kawamoto M, Chino N, Kangawa K \& Eto T 1998 Intermediate form of glycine-extended adrenomedullin is major circulating molecular form in human plasma. Biochemical and Biophysical Research Communications 245 551-555.

Kobayashi K, Kitamura K, Etoh T, Nagatomo Y, Takenaga M, Ishikawa T, Imamura T, Koiwaya Y \& Eto T 1996 Increased plasma adrenomedullin levels in chronic congestive heart failure. American Heart Journal 131 994-998.

Lewis LK, Smith MW, Yandle TG, Richards AM \& Nicholls MG 1998 Adrenomedullin(1-52) measured in human plasma by radioimmunoassay: plasma concentration, adsorption, and storage. Clinical Chemistry 44 571-577.

Nishikimi T, Saito Y, Kitamura K, Ishimitsu T, Eto T, Kangawa K, Matsuo H, Omae T \& Matsuoka H 1995 Increased plasma levels of adrenomedullin in patients with heart failure. Journal of the American College of Cardiology 26 1424-1431.

Okazaki T, Ogawa Y, Tamura N, Mori K, Isse N, Aoki T, Rochlle JM, Taketo MM, Seldin MF \& Nakao K 1996 Genomic organization, expression, and chromosomal mapping of the mouse adrenomedullin gene. Genomics 37 395-399.

Oldham CD, Li C, Feng J, Scott RO, Wang WZ, Moor AB, Girard PR, Huang J, Caldwell RB, Caldwell RW \& May SW 1997 Amidative peptide processing and vascular function. American Journal of Physiology 273 C1908-C1914.

Sakata J, Shimokubo T, Kitamura K, Nakamura S, Kangawa K, Matsuo H \& Eto T 1993 Molecular cloning and biological activities of rat adrenomedullin, a hypotensive peptide. Biochemical and Biophysical Research Communications 195 921-927.

Yamaguchi T, Baba K, Doi Y, Yano K, Kitamura K \& Eto T 1996 Inhibition of aldosterone production by adrenomedullin, a hypotensive peptide, in the rat. Hypertension 28 308-314.

Yasue H, Yoshimura M, Sumida H, Kikuta K, Kugiyama K, Jougasaki M, Ogawa H, Okumura K, Mukoyama M \& Nakao K 1994 Localization and mechanism of secretion of B-type natriuretic peptide in comparison with those of A-type natriuretic peptide in normal subjects and patients with heart failure. Circulation $\mathbf{9 0}$ 195-203.

Received 3 August 1998

Accepted 23 October 1998 